\title{
Regulação e controle ético de pesquisa em Psicologia Organizacional e do Trabalho
}

Adriano de Lemos Alves Peixoto ${ }^{1}$

Universidade Federal da Bahia, Salvador, BA, Brasil

$\overline{\text { Palavras-chave: }}$

ética;

ética em pesquisa;

ciência.

\section{Resumo}

O que é ética em pesquisa? Essa é a questão que dispara a reflexão apresentada neste texto. Na primeira seção, buscou-se demonstrar como pontos específicos do contexto atual de pesquisa no país polarizaram e distraíram a atenção de pesquisadores sobre essa importante questão. Na sequência, discute-se ética em pesquisa com base na lógica da ética profissional, o que justificaria que padrões de conduta e qualidade desse tipo de atividade devem ser exercidos pelos membros que fazem parte dessa comunidade. Mais do que se basear em instrumentos normativos que detalhem de forma extensiva os limites da ética em pesquisa, este trabalho assume que a reflexão ética deve se basear em princípios gerais que devolvem ao pesquisador, e não a um órgão externo, a responsabilidade pela conduta ética em pesquisa. E, por fim, apresentamos uma discussão sobre esses princípios e como eles podem ser operacionalizados na prática.

Regulation and ethical control of research in Work and Organizational Psychology

\section{Keywords:}

ethics;

research ethics;

science.

\begin{abstract}
What is research ethics? This is the question that triggers the reflections in this paper. In the first section we sought to demonstrate how specific issues of Brazil's current research environment have polarized and distracted attention from researchers on this important issue. We then discuss research ethics based on professional ethics literature, justifying why standards of conduct and quality of research activity should be controlled by members of this community. Rather than relying on legal instruments that extensively detail the limits of research ethics, this study assumes that ethical reflection should be based on general principles that remand to the researcher, not an external body, the main responsibility for ethical conduct in research. Finally, we present a discussion on how these principles can be operationalized in practice.
\end{abstract}

Regulación y control ético de la investigación en Psicología Organizacional y del Trabajo

Palabras-clave:

ética;

ética en la investigación; ciencia.

\begin{abstract}
Resumen
¿Qué es la ética en la investigación? Esta es la pregunta que desencadena la reflexión del presente texto. En la primera parte, hemos tratado de demostrar cómo las cuestiones específicas del contexto actual de la investigación, en el país, han polarizado y desviado la atención de investigadores sobre esta importante cuestión. En la secuencia, se discute ética en investigación con base en la lógica de la ética profesional, lo que justificaría que normas de conducta y calidad, de este tipo de actividad, se deben utilizar por los miembros que forman parte de esta comunidad. Más que basarse en instrumentos normativos que detallan ampliamente los límites de la ética en investigación, este trabajo asume que la reflexión ética debe fundamentarse en principios generales que devuelvan al investigador, y no un órgano externo, la responsabilidad de la conducta ética. Por fin, se presenta una discusión de estos principios y cómo ellos pueden ser operativos en la práctica.
\end{abstract}

\footnotetext{
Endereço para correspondência: Instituto de Psicologia, Universidade Federal da Bahia Rua Aristides Novis, 197 (Estrada de São Lázaro), Salvador, BA, Brasil 40210-730. Email: peixoto@hotmail.co.uk Como citar este artigo:

Peixoto, A. L. A. (2016). Regulação e controle ético de pesquisa em Psicologia Organizacional e do Trabalho. Revista Psicologia: Organizações e Trabalho, 16(4), 324-332. doi: $10.17652 /$ rpot/2016.4.12658
} 
A despeito de sua importância, e por mais contraditório que isso possa parecer, o debate sobre ética em pesquisa não tem evoluído de forma significativa ao longo dos anos. Neste início de século, ainda nos debruçamos sobre as mesmas questões básicas que já estavam postas no início dos anos sessenta e que continuaram sendo exploradas, ainda que com novas roupagens, nos anos noventa e seguintes. Essa constatação já sugere um elemento fundamental e ao mesmo tempo paradoxal do debate ético: ele está em constante movimento e renovação, mesmo que traga sempre as mesmas questões. A cada nova descoberta, a cada nova conquista, a cada novo campo de possibilidade de ampliação do conhecimento e de expansão dos métodos de investigação, surgem áreas e aspectos não explorados sobre os limites da ação do pesquisador, a forma de condução das pesquisas, a forma como se estabelecem as relações com os participantes da pesquisa e o uso que se faz das informações coletadas. Tal situação faz com que as questões éticas sejam sempre renovadas e raramente respondidas de forma definitiva (Bryman, 2005).

Nos últimos anos, observamos um importante e substancial crescimento e renovação do debate sobre ética em pesquisa em nosso país, tanto no âmbito acadêmico, quanto no profissional. De um lado, o debate se renova em função dos avanços tecnológicos e científicos que testam fronteiras do conhecimento e da técnica à disposição da sociedade, apresentando questões sobre os limites da ação humana sobre a natureza e sobre a própria sociedade, e levantando entre as pessoas questões polêmicas e não consensuais (Victora, 2014). Do outro lado, observamos uma expansão da profissão, que se mostra mais crítica em relação às desigualdades sociais (Conselho Federal de Psicologia [CFP], 2013) e que se move em direção a novos contextos de atuação. Nesse movimento, vêse indivíduos em condições de vulnerabilidade social (risco) que, muitas vezes, não compreendem completamente a extensão e as possíveis consequências da ação profissional e que, por este motivo, necessitam de algum tipo de tutela ou proteção como forma de garantia de seus direitos (British Psychological Society [BPS], 2014).

Parte significativa do atual debate sobre ética em pesquisa no país pode ser creditada à disputa que se estabeleceu, especificamente, em torno da forma de regulação da atividade de pesquisa científica envolvendo seres humanos. Diferentemente de outros países onde as diversas sociedades profissionais, conselhos científicos e órgãos estatais atuam ativa e paralelamente, orientando a atividade de pesquisa e estabelecendo códigos e regulações próprias, no Brasil, houve uma concentração no âmbito do Conselho Nacional de Saúde (CNS) que instituiu, via resolução normativa, um sistema de regulação ética de aplicação universal para toda e qualquer forma de pesquisa envolvendo seres humanos (Leitão, Falcão, \& Maluf, 2015). Esse sistema inclui o Conselho Nacional de Pesquisa (CONEP) - uma comissão que tem a função de implementar as normas e diretrizes regulamentadoras de pesquisas envolvendo seres humanos - e os Comitês de Ética em Pesquisa (CEPs), que são unidades colegiadas responsáveis pela avaliação, revisão e orientação ética de projetos de pesquisa.

Tal situação produziu um choque entre duas culturas de pesquisa distintas e, portanto, duas concepções bastante diferentes sobre o que podem ser considerados problemas éticos e como lidar com eles. De um lado dessa disputa colocou-se o modelo das ciências biomédicas, que segue uma tradição de proteção de direitos e bemestar dos sujeitos de pesquisa baseada na codificação das práticas e no controle externo das atividades de pesquisa, o padrão adotado pelo CNS. Do outro lado, encontramos o modelo das ciências humanas, ciências sociais e ciências sociais aplicadas (CHS), no qual uma maior ênfase é colocada em aspectos políticos e relacionais do processo de pesquisa (Guerriero \& Dallari, 2008), que está muito menos sujeito, portanto, à codificação (Hoeyer, Dahlager, \& Lynöe, 2005) e, consequentemente, ao controle externo. A regulação desse tipo de abordagem tradicionalmente se dá pela via de códigos que estabelecem princípios gerais que devem ser interpretados pelo pesquisador vis-à-vis cada situação encontrada, significando uma maior responsabilidade do pesquisador individual no controle ético da atividade de pesquisa.

Essa inadequação das CHS ao modelo de regulação proposto pode ser claramente percebida quando nos voltamos para os aspectos metodológicos que são característicos dessas ciências e que não se encaixam no padrão biomédico (Leitão et al., 2015). Podemos ver, por exemplo, nas pesquisas de natureza qualitativas, tão comuns nas CHS e de difícil compreensão por parte do modelo CNS/CONEP/CEP.

As tensões e contradições sobre a regulação das atividades de pesquisa se reatualizam e se expressam de forma clara no interior da psicologia. Em função de suas múltiplas origens, recortes epistemológicos e metodológicos, encontramos campos da Psicologia que se identificam com o modelo da ciências biomédicas, ao passo que outros se identificam mais com o modelo e as tradições das CHS, o que torna essa discussão particularmente sensível e importante, uma vez que aqui também não existe consenso sobre como regular a atividade de pesquisa.

Um exemplo desse tipo de dificuldade foi expresso pela Associação Brasileira de Psicologia Organizacional e do Trabalho (SBPOT) em um manifesto no qual a entidade expressava sua discordância quanto à definição exclusiva da Psicologia como uma ciência da área de saúde. Entre os vários problemas elencados, a entidade deixava claro que as exigências regulatórias para pesquisa decorrentes da adoção dessa definição teriam "consequências nefastas para a produção do conhecimento científico" (p. 3) pela introdução de elementos de difícil operacionalização e até mesmo contrários à tradição e prática de pesquisa na área (SBPOT, 2008).

Nas CHS cabe ao pesquisador individual avaliar por si mesmo como se portar e conduzir o processo de investigação à medida que ele se desenvolve, em função da maneira como se constitui a interação entre pesquisador e participantes. Isso é patente, por exemplo, na forma de obtenção do consentimento livre e esclarecido que está muito associada à confiança que se estabelece em função dessa relação pesquisador-participantes; na dificuldade de uma definição a priori exata do número de casos, o que é determinado em função de saturação teórica (Fontanella et al., 2011) em relação a um conteúdo; e na dificuldade de estabelecimento de um cronograma rígido para a realização da pesquisa. Todos estes elementos estão sujeitos a contingências que não estão sob controle do pesquisador (Victora, 2014). Como se isso tudo não fosse o suficiente, não podemos desconsiderar que a aplicação de princípios regulatórios incompatíveis com a natureza da pesquisa pode vir a se tornar uma forte barreira ao avanço do conhecimento científico na área. Esses foram alguns dos argumentos principais utilizados por pesquisadores e entidades científicas para a defesa de uma resolução específica que contemplasse a área das $\mathrm{CHS}$ e base da reação contra a aplicação universal do modelo biomédico de regulação predominante no CNS (Borges, Barros, \& Leite, 2013)2.

A solução encontrada para esse conflito a partir da resolução 510/2016 do CNS reconhece as especificidades da CHS na medida em que propõe que o grau de risco passa a ser o elemento definidor da necessidade de regulação externa e estabelece múltiplas

\footnotetext{
Após um longo embate, o CNS publicou a resolução de número 510/2016 que dispõe sobre normas de pesquisa aplicáveis às ciências sociais e humanas.
} 
formas de obtenção do consentimento à participação, que podem ser adotadas em função do tipo de pesquisa que se está desenvolvendo. Assim, em lugar de um modelo de regulação externa universal - com submissão necessária de todos os projetos de pesquisa à revisão de um CEP - a nova resolução introduziu um sistema misto onde parte importante do controle ético da pesquisa é devolvida ao próprio pesquisador. Ele agora só é obrigado a se submeter a controle externo em função do grau de risco oferecido pela sua pesquisa. Outro avanço significativo foi o reconhecimento de que os Comitês de Ética devem ser compostos por profissionais das áreas nas quais a pesquisa é realizada, uma vez que eles têm um maior domínio sobre o que é ou não é considerado procedimento ético dentro de uma área específica da atividade científica. Diante do exposto, podemos afirmar que, ainda que a resolução 510/2016 tenha sido editada pelo CNS, ela rompe com a lógica da aplicação universal do modelo bioético, superando barreiras e entraves ao avanço das $\mathrm{CHS}$.

É razoável supor que, em função de sua importância, essa disputa tenha desviado a atenção de outros elementos igualmente significativos que têm recebido relativamente pouca atenção nesse debate nos últimos anos. Entretanto, por mais importante que esta questão da regulação da atividade de pesquisa seja, ela não esgota a discussão sobre ética em pesquisa.

Neste contexto, precisamos expandir a nossa atenção e reconhecer que o debate sobre ética em pesquisa deve ser construído a partir da compreensão do lugar e da importância da ciência na sociedade, da necessidade de manutenção da confiança que esta mesma sociedade tem em seu papel social e em sua capacidade de produção dos resultados esperados. Com base nessa perspectiva, o pano de fundo necessário para uma adequada compreensão do debate ético pode e deve ser localizado nas discussões e normas que emergem a partir da forma como os membros desse complexo empreendimento social cooperam e atuam (Whitbeck, 1995). É responsabilidade do pesquisador proteger tanto os direitos dos participantes quanto a reputação do seu campo de conhecimento (Aguinis \& Henle, 2004). Esse é um dos motivos pelos quais Resnik (2005) aponta que o desrespeito às normas éticas afeta a imagem pública e reduz o suporte social à ciência.

Com isso, é possível afirmar que os padrões éticos em pesquisa se desenvolvem a partir de duas bases principais, visceralmente imbricadas entre si: uma vertente que deriva da necessidade de seguir padrões morais comumente aceitos pela sociedade, como a honestidade; e outra que se organiza a partir da necessidade de avançar os objetivos da ciência (Resnik, 2005) e que encontra suporte na natureza da atividade científica, como a objetividade e a confiança, sendo que esses padrões se aplicam às diversas fases do processo de pesquisa, que se estendem desde a sua preparação até a publicação (disseminação) dos seus resultados (BPS, 2014). É nessa direção que a American Psychological Association (APA) indica que a reflexão ética relacionada à atividade científica deve se desenvolver, de forma a garantir três objetivos principais: a acurácia do conhecimento científico; a proteção aos diretos e ao bem-estar dos participantes da pesquisa (é aqui que está localizada toda a discussão sobre governança e controle ético da pesquisa); e a proteção aos direitos de propriedade intelectual que derivam da atividade científica (APA, 2010b).

Diante do exposto, este ensaio tem por finalidade mostrar que necessitamos ampliar o debate ético para além da discussão sobre regulação externa de atividade de pesquisa, em direção à reflexão sobre ética e formação de pesquisadores e sobre a função social da pesquisa científica; que, apesar da importância de normas e regulações legais, a responsabilidade primordial pela condução ética em pesquisa deve recair sobre o próprio pesquisador, que se deve guiar por princípios éticos reconhecidos e aceitos pela sua comunidade de práticas, que tem a capacidade e o dever de estabelecer princípios e limites sobre o que deve ser aceito ou não como comportamento ético em pesquisa; e apresentar, à luz de princípios éticos gerais, quais comportamentos devem ser considerados infrações éticas na pesquisa.

\section{Ética em pesquisa como ética profissional}

A produção do conhecimento não é uma atividade neutra. Ela pressupõe uma hierarquia entre pesquisador e pesquisado, entre aquele que tem um objetivo específico no processo de coleta de dados (o pesquisador) e aquele que fornece a informação (o sujeito, o pesquisado, o informante, o participante ${ }^{3}$ ), que usualmente tem muito menos conhecimento e domínio sobre o processo do que a outra parte envolvida na pesquisa. Essa diferença sugere que pesquisador e pesquisado têm interesses e agendas distintas em relação ao processo da pesquisa, configurando uma situação de clara diferença de poder, mesmo que o pesquisador atue para minimizar essas diferenças (BPS, 2014). Por outro lado, um histórico de simulações, violações e exposições desnecessárias a riscos, sem claros benefícios ao avanço do conhecimento que justifiquem essa situação, levantam a questão sobre ética em pesquisa (Borges et al., 2013).

O ponto de partida para a compreensão e a localização dos problemas éticos (na atividade de pesquisa) se dá no reconhecimento de que vivemos em um mundo multi-fragmentado, fruto do processo de modernização da sociedade, que, pautado pela racionalidade, vai se tornando cada vez mais complexo e diferenciado, vindo a se caracterizar por aquilo que Durkheim (1999) denomina de solidariedade orgânica. Ou seja, a coesão social é baseada na interdependência que as pessoas e grupos têm umas em relação às outras, onde quer "que as pessoas vivam uma vida comum [que] resulte da divisão do trabalho social" (p. 98).

Para Gonzalez (2000), essa fragmentação da sociedade passa a exigir que a ação dos indivíduos se conforme a múltiplos e particulares tipos de legalidade como parte desse processo de "regionalização da atividade humana" (p. 807), se afastando de concepções tradicionais que concebiam a ética como um saber capaz de orientar de forma global a vida humana, e impondo uma necessidade de resposta desses indivíduos às demandas normativas derivadas de seus espaços específicos de atuação. Nesse contexto, a moral se compreende como uma dimensão normativa das condutas humanas que é definida por sua universalidade, se expressando em normas e padrões de alcance geral. Já a ética pode ser compreendida como um ramo da filosofia moral que se volta para a compreensão sobre a forma de ser no mundo, como um método, procedimento ou perspectiva sobre como analisar e agir frente a questões e problemas complexos (Resnik, 2015) que se apresentam em nosso dia a dia.

A ética se desenvolve em contextos históricos específicos e se volta para a compreensão de comportamentos individuais envolvendo a reflexão, a sistematização, a defesa e a sugestão sobre o certo e o errado no comportamento, se manifestando sob a forma de normas de conduta que são tão provisórias como o são as ações humanas (Passos, 2007). Posto de outra forma, a ética,

\footnotetext{
Já há algum tempo vem sendo dada preferência ao uso da palavra "participante" em lugar de "sujeito" da pesquisa, que tem uma conotação mais passiva. Isso decorre do reconhecimento da autonomia e do poder de agência do indivíduo que participa da pesquisa e do seu direito de se retirar a qualquer tempo sem qualquer tipo de penalidade (BPS, 2014).
} 
diferentemente da moral, "[...] não é um padrão geral de conduta, mas sim o padrão de uma profissão particular, uma ocupação, instituição ou grupo dentro da sociedade" (Resnik, 2005, p. 14). Isso ajuda a explicar por que as pessoas, apesar de reconhecerem algumas normas éticas em comum, interpretam, aplicam e ajustam essas normas de diferentes formas à luz de seus distintos valores e experiências de vida (Resnik, 2015). Os dilemas éticos surgem justamente porque frequentemente não há concordância entre os cientistas sobre que padrões de conduta devem guiar a produção do conhecimento e como normas e procedimentos devem ser interpretados ou aplicados (Bastos, Yamamoto, \& Rodrigues, 2013; Whitbeck, 1995).

Parte importante dessa nossa ação no mundo, da interação que estabelecemos com outras pessoas e com a sociedade, se dá a partir do trabalho profissional que desenvolvemos, aqui considerado como uma forma de atividade social e que, por este motivo mesmo, deve ser organizada e sujeita à regulação (Durkheim, 1957) por parte da sociedade. Para Ardagh (2007), uma profissão se define, em linhas gerais, a partir de um conjunto de características principais: (a) ela atende a uma necessidade humana; (b) ela aplica conhecimento específico para o atendimento dessa necessidade; (c) ela recebe uma delegação de autoridade por parte da sociedade que Ihe confere poder (baseado na confiança) para a utilização desse conhecimento; (d) ela possui padrões implícitos e explícitos de qualidade e competência; (e) ela normalmente necessita de algum tipo de treinamento formal de longa duração como forma de acesso à profissão. Não é por outro motivo que um componente fundamental de toda profissão consiste, justamente, no desenvolvimento de um código de ética próprio que permite a uma determinada comunidade de prática estabelecer e regular padrões de conduta, qualidade, pertencimento e reconhecimento social autoaplicáveis (Durkheim, 1957), como forma de controle do poder e manutenção da confiança que lhes foram delegados pela sociedade.

Isso ajuda a compreender por que o debate ético sobre a forma de regulação da atividade de pesquisa no Brasil assumiu tamanha importância para as CHS e para a Psicologia Organizacional e do Trabalho: ele se coloca no centro das discussões sobre identidade profissional. É sobre esse tipo de conflito que Hoeyer et al. (2005) chamam a nossa atenção ao afirmarem que "é [...] importante evitar avaliar uma tradição [de pesquisa] com base nos padrões da outra" (p. 1742).

Ao considerarmos a atividade de pesquisa uma prática profissional, fica fácil entender que ela se refere a uma atividade cujos princípios, forma, características e objetivos são apenas claramente compreendidas por um grupo específico de pessoas (os pesquisadores). Isso ocorre justamente por serem suas atividades específicas a esse mesmo grupo, daí porque transgressões sobre as condutas esperadas somente encontram repercussão junto à sociedade quando elas se referem a situações limites. Essa condição permite entender porque um sistema de moral será sempre afeito a um grupo e somente pode funcionar se for protegido pelos membros desse grupo, que são investidos de autoridade para tanto (Durkheim, 1957). É exatamente isso o que vemos em Resnik (2005), por exemplo, ao discutir a necessidade de algum tipo de treinamento relacionado à ética em pesquisa com estudantes. Ele sugere que [...] "alguns conceitos e princípios éticos só podem ser aprendidos a partir da compreensão e da prática de uma profissão" (p. 5, tradução do autor).

A centralidade e a importância da ética profissional para correta compreensão das tensões que envolvem parte significativa do debate ético recente em nosso país podem ser percebidas já na própria gênese das discussões atuais sobre bioética, localizada nos Julgamentos de Nuremberg, conduzidos em 1947 pelo Tribunal Militar Americano, e destinados a julgar médicos nazistas acusados de tortura e da condução de experiências desumanas em prisioneiros de campos de concentração. Para a acusação, aquele não era um julgamento de assassinato comum, uma vez que os acusados, por serem médicos, haviam prestado o juramento de Hipócrates e se comprometido com o princípio da benevolência de não causar dano. Já a defesa contra argumentou que os médicos cumpriam ordem do Estado, que sua ação buscava a realização do bem comum, que este se sobrepunha ao interesse do indivíduo, e que suas pesquisas seguiam um padrão internacionalmente generalizado de pesquisa. Assim, um tema recorrente do julgamento foram os limites e a capacidade dos ideais morais da profissão médica de servirem de guia ético à pesquisa sem colocar em risco a proteção dos direitos dos participantes (Shuster, 1997).

A partir desse ponto, consolida-se o principio básico da ética em pesquisa, no qual o bem-estar do participante individual tem precedência sobre todos os demais interesses relacionados à pesquisa. Esse histórico também ajuda a compreender o motivo pelo qual ética em pesquisa se tornou um conceito mais desenvolvido no campo das ciências biomédicas (European Union [EU], 2013).

O poder da ciência e do seu impacto social "impõem a necessidade de padrões de controle de qualidade para a atividade científica, o que, por sua vez, conduz de forma inexorável para o caminho da profissionalização" (Resnik, 2005, p. 34). Em suma, no contexto da pesquisa científica, a ética se refere a um conjunto de orientações e diretrizes que permitem ao pesquisador avaliar, revisar e fazer cumprir princípios éticos usualmente aceitos para esse tipo de prática (Aguinis \& Henle, 2004), no que tange a objetivos, métodos, práticas e formas de difusão do conhecimento.

Esses princípios são característicos e específicos a determinadas comunidades de prática (profissões) que têm, elas mesmas, a responsabilidade de definir e circunscrever quais comportamentos são ou não adequados aos seus membros em função de suas competências específicas. Isso faz com que a questão da ética em pesquisa deva ocupar um lugar central na reflexão sobre o fazer científico e na prática de pesquisa. Esse também é o motivo pelo qual não podemos aplicar de forma indistinta o mesmo modelo de regulação para os diferentes campos do conhecimento que se desenvolvem e se organizam com base em distintas práticas e tradições de pesquisa. Tendo demonstrado a necessidade de que controles éticos sobre a atividade de pesquisa sejam construídos por comunidades de prédicas específicas (profissões), impõe-se a necessidade de demonstrar os limites do controle externo e a importância da formação do pesquisador para um efetivo fazer ético em pesquisa. É isso que discutiremos na próxima seção.

\section{Princípios éticos guiando a atividade de pesquisa}

A pesquisa com seres humanos, na Psicologia de um modo geral, e na Psicologia Organizacional e do Trabalho de forma específica, é muito ampla e variada, envolvendo um número incontável de diferentes fenômenos psicológicos que, por sua vez, se manifestam em múltiplos e distintos níveis de análise. Essa pluralidade é expressão das distintas origens e percursos trilhados ao longo do processo de constituição de nossa área. São inúmeras teorias, métodos e sistemas que se constroem sobre diferentes pressupostos ontológicos, epistemológicos e metodológicos.

De uma perspectiva metodológica, essa pluralidade se manifesta em um contínuo em cujo um dos polos encontram-se procedimentos que coletam dados sem que haja qualquer forma de identificação dos participantes (que permanecem anônimos) sobre 
assuntos não sensíveis, onde o processo de coleta, ou a natureza da informação buscada, não gera nenhum tipo de risco mais expressivo, além daqueles comumente encontrados na experiência do cotidiano. No polo oposto, encontramos situações nas quais dados sensíveis são coletados junto a populações vulneráveis, incapazes de pleno consentimento, necessitando de alguma forma de tutela e proteção com a finalidade de garantir que algum de seus direitos básicos (dignidade, privacidade, integridade e bem-estar) não serão significativamente agredidos pela pesquisa (BPS, 2014).

Essa ampla gama de possibilidades se mostra incapaz de ser coberta por instrumentos regulatórios que apontem de maneira ampla, explícita, objetiva e definitiva, formas sobre como proceder para cada situação encontrada na pesquisa científica (Tri Council Policy Statement [TCPS2], 2014), como reconhecem os conselhos de pesquisa canadenses. Sobre esse ponto específico, a Sociedade Britânica de Psicologia sugere que a existência de códigos normativos extensos e detalhados, além de efetivamente não garantir um comportamento ético, tende a estimular uma postura mecânica e burocrática por parte do pesquisador, que é tentado a substituir a reflexão ética sobre problemas e dilemas enfrentados em situações específicas pelo fiel cumprimento da letra da lei. A norma substitui a reflexão. Da mesma maneira, o recurso a instrumentos detalhados de regulamentação dificultam a ação dos comitês institucionais de revisão ética (os nossos CEPs) que vão se mostrando incapazes de lidar com situações nuançadas específicas não cobertas pela legislação (BPS, 2014).

Esse padrão de entendimento também se encontra expresso no referencial europeu para ética em pesquisa quando declara que

Ainda que muitas questões éticas sejam codificadas utilizando-se de instrumentos legais, ética em pesquisa vai muito mais além do que a definição da diferença entre o legal e o ilegal. A ética em pesquisa requer uma valiação independente das atividades de pesquisa e de suas possíveis consequências. É uma questão de consciência e de olhar para além dos objetivos da pesquisa, para as consequências para todas as pessoas envolvidas e os possíveis impactos na sociedade como um todo (EU, 2013, p. 22, tradução do autor).

Essas posições apontam claramente que a forma de condução ética consiste, em essência, na "[...] aplicação de um juízo moral informado, baseado em um conjunto de princípios morais" (BPS, 2014 , p. 7, tradução do autor). Ou seja, a reflexão sobre ética em pesquisa psicológica deve se apoiar, portanto, em um conjunto de princípios gerais que expressem valores que são fundamentais para a profissão e não em procedimentos formais. Ou, ainda, a responsabilidade primordial pela ética em pesquisa deve ser do pesquisador e não de um organismo externo.

O Código de Conduta e Princípios Éticos para Psicólogos da APA (APA, 2010a) também assume essa mesma perspectiva quando declara sua opção por princípios gerais de natureza aspiracional, em detrimento de padrões legais impositivos, prescritivos, como forma de promoção da conduta ética entre seus membros, ao tratar de questões relacionadas à pesquisa psicológica:

Princípios gerais, em oposição a padrões éticos, são aspiracionais em sua natureza. Seu objetivo consiste em guiar e inspirar psicólogos em direção aos ideais éticos mais elevados da profissão. Princípios gerais, em contraste com padrões éticos, não representam obrigações e não devem formar a base para a imposição de sansões. Basear-se em princípios gerais para algumas dessas ações distorce tanto o seu sentido como propósito (APA, 2010a, tradução do autor).
Essa importância dos princípios morais gerais orientando a ética aplicada à pesquisa se manifesta de forma expressa nos códigos de diversos organismos que apoiam e financiam atividades de pesquisa e associações profissionais, como podemos observar na Tabela 1, que sintetiza os princípios que orientam a pesquisa da APA, da BPS e da União Europeia. Apesar de uma aparente diferença, um olhar mais próximo mostra que, na verdade, eles exprimem os mesmos ideais fundamentais, ainda que apresentados com nomes distintos. Todos eles são voltados para a consecução de, pelo menos, um dos três princípios mais gerais já apresentados na introdução deste artigo: a acurácia do conhecimento científico (ciência); a proteção aos diretos e ao bem estar dos participantes da pesquisa (direitos humanos); e a proteção aos direitos de propriedade intelectual que derivam da atividade científica.

Tabela 1

Princípios aplicados à pesquisa psicológica

\begin{tabular}{llll}
\hline \multicolumn{1}{c}{ BPS (BPS, 2014) } & APA (APA, 2010a) & EU (EU, 2010) & CFP (2014) \\
\hline $\begin{array}{l}\text { Respeito por auto- } \\
\text { nomia, privacida- } \\
\text { de e dignidade das } \\
\text { pessoas e comuni- } \\
\text { dades }\end{array}$ & $\begin{array}{l}\text { Beneficência e } \\
\text { não maleficência }\end{array}$ & $\begin{array}{l}\text { Proteção de } \\
\text { dados e priva- } \\
\text { cidade }\end{array}$ & $\begin{array}{l}\text { Proteção ao } \\
\text { participante da } \\
\text { pesquisa }\end{array}$ \\
$\begin{array}{l}\text { Integridade cien- } \\
\text { tífica }\end{array}$ & $\begin{array}{l}\text { Fidelidade e res- } \\
\text { ponsabilidade }\end{array}$ & $\begin{array}{l}\text { Consenti- } \\
\text { mento }\end{array}$ & Consentimento \\
$\begin{array}{l}\text { Responsabilidade } \\
\text { social }\end{array}$ & Integridade & $\begin{array}{l}\text { Balano de } \\
\text { danos bene- } \\
\text { fícios }\end{array}$ & Anonimato \\
$\begin{array}{l}\text { Maximinação do } \\
\text { benefício e mini- } \\
\text { mização do risco }\end{array}$ & $\begin{array}{l}\text { Justiça } \\
\text { Respeito pelos } \\
\text { direitos e dignida- } \\
\text { de das pessoas }\end{array}$ & $\begin{array}{l}\text { Proteção ao } \\
\text { participante } \\
\text { da pesquisa }\end{array}$ & Acesso \\
\hline
\end{tabular}

Não chega a ser uma surpresa que os principais códigos de ética e conduta dos países ocidentais sejam muito parecidos entre si. Afinal, todos eles expressam o respeito aos direitos fundamentais (EU, 2013) previstos na legislação internacional e compartilhados como uma herança social e cultural comum a esses países.

Do exposto, depreende-se que os mesmos princípios gerais podem se manifestar de múltiplas formas distintas, o que sugere que não é a forma de regulação que garante a ética, mas os princípios que guiam as formas de regulação e, mais importante ainda, a maneira como o pesquisador se apropria desses princípios e os utiliza. Em outras palavras, o núcleo de um agir ético está localizado no comportamento do pesquisador quando desenvolve a pesquisa, que precisa ser adequadamente educado, instruído sobre princípios e procedimentos éticos.

Nesse ponto o nosso desafio passa a ser demonstrar como a aplicação de um conjunto de princípios gerais e abstratos pode ser utilizado como guia na condução da atividade de pesquisa. Na próxima seção, apresentaremos alguns comportamentos e procedimentos que, refletindo os princípios gerais indicados, são condenados pela comunidade científica, sendo considerados violações éticas na pesquisa. Como se poderá observar, vários desses procedimentos não são passíveis de serem coibidos, ou mesmo identificados, com base em um modelo que essencialmente se apoie sobre regulação externa, ressaltando a importância, uma vez mais, de ação direta do pesquisador. 


\section{Princípios éticos aplicados à pesquisa}

\section{Princípio: Garantia da acurácia do conhecimento científico}

A má conduta científica (scientific misconduct) (EU, 2013; Resnik, 2005; UK Integrity Research Office, 2009), em alguns casos também chamada de comportamento inapropriado em pesquisa (Research Councils UK [RCUK], 2013), envolve um amplo conjunto de diferentes práticas que são contrárias aos valores científicos, e que pelas suas consequências têm o potencial de minar a confiança da sociedade na atividade científica. Normalmente esse tipo de prática ocorre após a realização da pesquisa se colocando, portanto, fora do alcance de qualquer forma de procedimento de revisão ética (EU, 2010), como aqueles realizados pelos CEPs.

Essas práticas são polideterminadas, distribuindo-se ao longo de um amplo espectro. Elas vão desde pequenos equívocos que ocorrem de forma ocasional e inadvertida, mas decorrente de um comportamento negligente ou imperito por parte do pesquisador, estendendo-se até situações de deliberada intenção de apropriação indevida de dados, ideias e falsificação de resultados. Em um extremo, as violações éticas costumam emergir em função de problemas na formação dos pesquisadores, que não têm o necessário domínio sobre métodos e técnicas aplicadas (ou seja, cometem erros), pela inexistência ou inadequada manutenção de registros de procedimentos e/ou pela inexistência de documentação adequada. Questões dessa natureza normalmente podem ser superadas com treinamento dado aos pesquisadores (Bucher-Maluschke, 2006; RCUK, 2013) ou pela maior atenção dada à forma como a pesquisa é efetivamente desenvolvida.

Para alguns, a localização dessa necessidade de domínio teórico e metodológico sobre a prática da pesquisa com vistas ao avanço do conhecimento científico no campo ético pode parecer uma surpresa, mas ela está clara e abertamente expressa em um documento recentemente publicado pela Alliance for Organizational Psychology (AOP, 2016) ${ }^{4}$, onde se expressa um consenso de que a qualidade, impacto e reputação da pesquisa é um dos "é o problema principal que impede a condução de pesquisas éticas, rigorosas e relevantes em Psicologia Organizacional e do Trabalho, de forma específica, e na Psicologia e possivelmente em outras ciências de forma mais geral" (p. 1, tradução do autor).

No outro extremo do espectro da má conduta científica encontramos a fabricação, falsificação e plágio, que são considerados como sérias violações dos princípios básicos da honestidade e da confiança na ciência. Como não existe uma delimitação precisa sobre exatamente quais comportamentos se enquadram nessa categoria, alguma variação na delimitação desse tipo de conduta pode ser encontrada em diferentes autores e organismos, como percebemos, por exemplo, nas definições do UK Integrity Research Office (UKRIO, 2009) e no Research Councils UK (RCUK, 2013), que incluem nessa categoria a deturpação (misrepresentation) de dados, interesses, qualificações e envolvimento.

A fabricação consiste na criação de dados falsos ou de qualquer outra informação/documentação relacionada à pesquisa, incluindo o consentimento dado pelos participantes. A falsificação consiste na manipulação inapropriada e/ou na seleção de dados de modo a produzir um resultado diferente daquele que seria encontrado através de uma análise criteriosa. Essa é uma questão delicada, uma vez que existe grande discricionariedade por parte do pesquisador

4 A AOP é formada pela Organizational Psychology Division of the International Association for Applied Psychology (Divisão 1 da APA), European Association for Work and Organizational Psychology (EAWOP), e pela Society for Industrial and Organizational Psychology (SIOP). sobre o tipo de análise estatística que ele considera mais apropriada para a sua pesquisa, mas não é disso que se trata a falsificação. Aqui, a manipulação é deliberada, intencional e ocorre quando: (a) o pesquisador falha em informar sobre dados e evidências que não suportam suas hipóteses, (b) busca fazer com que os dados pareçam melhores do que eles efetivamente são, (c) o pesquisador desenha um experimento ou uma investigação de modo a produzir um resultado que ele tem grande evidência do que encontrará, (d) ou ainda ele deliberadamente evita uma investigação capaz de produzir um resultado negativo para suas pesquisas (Resnik, 2005).

A deturpação (misrepresentation) de dados consiste na deliberada ou na negligente supressão de informações responsáveis por produzir uma interpretação de resultados enviesada. Nesse caso, os dados foram honestamente coletados e registrados, mas houve desonestidade na sua apresentação (Resnik, 2005). Aqui, mais uma vez, surgem questões sobre os limites da manipulação da análise estatística de dados e da delimitação clara sobre o que constitui um comportamento inaceitável na pesquisa. Entretanto, é importante ter em perspectiva que a má conduta se caracteriza por uma deliberada intenção de fraudar os resultados da pesquisa e, por essa razão, a intenção do pesquisador é fundamental na determinação desse tipo de infração ética.

O plágio consiste na apropriação indevida de ideias, trabalho ou propriedade intelectual de outras pessoas sem o seu conhecimento ou permissão. De acordo com Resnik (2005) as recompensas da atividade científica incluem reconhecimento, prestígio, respeito e prêmios que decorrem do trabalho realizado. Assim, o devido crédito deve ser dado a todos os que efetivamente colaboram para o desenvolvimento de uma atividade científica de acordo com a sua contribuição específica. Como diz Resnick (2005): “Quando um princípio de crédito não opera na ciência, os cientistas podem se sentir menos motivados para fazer pesquisa e eles podem se tornar relutantes em compartilhar informação, uma vez que suas ideias podem ser roubadas" (p. 54, tradução do autor).

A partir desse princípio de conceder crédito a quem de direito emerge uma questão complexa, que é a chamada autoria honorária (Resnik, 2005). Ela se caracteriza quando um pesquisador tem o seu nome incluído em um trabalho sem que dele tenha efetivamente participado. A questão da autoria será tratada mais abaixo de forma específica quando falarmos de proteção aos direitos intelectuais.

As más condutas atentam contra a atividade científica de duas formas diferentes: elas não permitem a verificação independente dos resultados encontrados, comprometendo a objetividade da ciência (Resnik, 2005), e elas distorcem a base do conhecimento existente ao darem a impressão de que existem mais evidências ou suporte empírico para determinados resultados e teorias do que aquilo que realmente está disponível (APA, 2010b). Esses são os motivos pelos quais elas devem ser consideradas como infrações éticas. Medidas e procedimentos de denúncia e enfrentamento dessas questões devem ser incentivadas e aplicadas.

\section{Princípio: Proteção dos direitos e bem-estar dos participantes}

Para Barret (2010) a proteção aos direitos e ao bem estar físico e mental dos participantes da pesquisa é um princípio que atravessa todos os códigos de ética em pesquisa na Psicologia. Como princípio geral, ela emerge da necessidade de proteção dos princípios da dignidade humana, dos direitos humanos e das liberdades fundamentais, devendo os interesses e o bem-estar dos indivíduos prevalecer sobre o interesse exclusivo da ciência (Organização das Nações Unidas para a Educação, a Ciência e a Cultura [UNESCO], 
2006), sendo o bem estar definido como a qualidade como a qual a pessoa experimenta a vida em todos os aspectos (TCPS2, 2014).

Nos códigos e regulamentações sobre ética em pesquisa, esse princípio se materializa na noção de risco definida como possibilidade de danos à dimensão física, psíquica, moral, intelectual, social, cultural do ser humano, em qualquer etapa da pesquisa e dela decorrente. Ainda que existam diversos tipos e níveis de risco distintos, um parâmetro básico de avaliação a ser levado em conta pelos pesquisadores estabelece que o risco não deve ser maior do que aquele ao qual a pessoa está exposta no seu dia a dia. Para além desse ponto, deve-se estar atento às consequências da pesquisa e formas de minimização de risco precisam ser adotadas de modo a garantir o bem-estar dos participantes.

Como já vimos, o consentimento informado surge como mecanismo básico de proteção ao participante, que pode decidir livremente se deseja tomar parte de uma pesquisa, se deseja desistir de participar e ainda solicitar que quaisquer dados ou informação que tenha fornecido seja destruída. Os procedimentos relativos à obtenção do consentimento devem seguir um princípio de proporcionalidade aos riscos envolvidos e à natureza da participação (BPS, 2014), exatamente um dos objetivos centrais que se buscar atingir com a resolução 510/2016 do CNS. Isso significa que, por exemplo, para situações nas quais o dado coletado é anônimo na origem e sobre tema que não expõe o participante a risco, como é o caso da maioria dos estudos na área de POT, a simples concordância em participar, ou nos casos das coletas online, o ato de prosseguir respondendo ao questionário, são considerados formas adequadas e suficientes para o consentimento (BPS, 2014).

Existem três dimensões principais relacionadas ao consentimento para participação em pesquisa que precisam ser levadas em consideração para determinação da forma como esse consentimento deve ser obtido. Elas são consideradas condições necessárias no processo de tomada de decisão informada por parte participante: informação adequada, voluntariado e competência (EU, 2013).

Informação adequada significa que o participante deve receber todas as informações relevantes sobre o que se espera dele, como a coleta de dados irá se desenvolver, o que será feito com os dados coletados, e quais as possíveis consequências de sua participação. $\mathrm{O}$ voluntariado se refere à situação na qual o participante decide por livre e espontânea vontade tomar parte na pesquisa sem nenhuma forma de coerção ou pressão externa. Nos casos em que a pessoa não tem condições plenas condições de compreender o procedimento de pesquisa, não é competente para tal, significa que ela deve estar sob tutela ou guarda de alguma outra pessoa ou instituição que, neste caso, devem ser responsáveis por autorizar e supervisionar a sua participação. Esse é o caso, por exemplo, de pesquisas com crianças que não têm condições plenas de entender o que está acontecendo com elas e que, portanto, não são competentes para consentir plenamente. Aqui, deve-se buscar autorização dos pais ou responsáveis (BPS, 2014).

Em algumas situações de pesquisa é fundamental que o participante não tenha conhecimento prévio e completo sobre o que está sendo investigado, uma vez que essa informação pode distorcer os resultados da pesquisa. Nesse caso, estamos diante do uso de engano (deception) na relação com o participante, o que contraria alguns dos princípios acima explicitados. Há de se ter em vista que esse tipo de procedimento só é admissível caso outras técnicas de investigação não sejam consideradas adequadas e que o estudo tenha real valor educacional, científico ou aplicado (APA, 2010a).

Toda informação coletada de participantes da pesquisa deve ser considerada a priori como confidencial. Qualquer outra disposição em sentido contrário deve ser previamente informada aos participantes, e seus limites, negociados. As consequências desse entendimento muitas vezes se expressam quando o psicólogo/ pesquisador conduz uma investigação como parte do trabalho que realiza para algum tipo de empregador/contratante (seja ele organização pública, privada ou de terceiro setor), que, tendo interesse em situações específicas, pode vir a pressionar pela identificação de um participante qualquer. Deve-se ressaltar, entretanto, que o direito à confidencialidade pode e deve ser relativizado quando confrontado com um princípio mais elevado como, por exemplo, a proteção e a manutenção da integridade e bem-estar de um participante (BPS, 2014).

\section{Princípio: Proteção à propriedade intelectual}

A noção de propriedade intelectual se refere à proteção de uma produção do intelecto, da mente humana. Ela existe para permitir que criadores e proprietários se beneficiem de sua produção, funcionando como uma forma de estímulo à inovação e à criação. Para a Organização Mundial de Proteção a Propriedade Intelectual (WIPO) existem três razões básicas que justificam a sua adoção:

Primeiro, o progresso e o bem estar da humanidade repousam na sua capacidade de criar e inventar novos trabalhos nas áreas de tecnologia e cultura. Segundo,a proteção legal das novas criações encouraja o compromisso de novos recursos para inovações adicionais. Terceiro, a promoção e a proteção da propriedade intelectual estimula o crescimento econômico, cria novos empregos e industrias, e aumenta a qualidade e o aproveitamento da vida (WIPO, s/d, tradução do autor).

Ainda que a legislação sobre a proteção aos diretos de propriedade varie de um país para o outro, elas têm a função de preservar para o autor o direito a certas formas específicas de expressão da ideia, e não sobre a ideia em si mesma. Isso significa que certas partes dessas ideias podem ser copiadas, desde que isso não signifique a redução do seu valor comercial, ou ainda, que sejam destinadas ao uso educacional (Resnik, 2005). Uma explanação extensa sobre as múltiplas formas de propriedade intelectual fogem ao escopo deste artigo. Assim, vamos nos concentrar naquelas mais próximas da atividade científica em Psicologia Organizacional e do Trabalho, que é o direito autoral e como isso se relaciona com ética em pesquisa.

O princípio básico que norteia esta discussão é o de que autoria é devida a quem tem direito. Assim, indivíduos só devem receber crédito se eles de fato contribuíram de forma significativa para a realização do trabalho. De acordo com a APA (2010b), por contribuição científica significativa compreende-se: "formulação de problemas e hipóteses, estruturação de desenho experimental, organização e condução das análises estatísticas, interpretação de resultados ou redação de partes significativas do texto" (p. 18). Nessa direção, a ordem de autoria deve refletir a contribuição efetiva para o trabalho.

Em muitos casos de má conduta científica tem-se constatado que coautores alegam desconhecer detalhes fundamentais das pesquisas e, por este motivo, não se responsabilizam por problemas identificados. Essa é uma questão delicada, uma vez que os autores devem ser passíveis de responsabilização pelas consequências do seu trabalho, sejam elas positivas ou negativas. Como coloca Resnik (2005): [...] "aqueles que recebem o benefício do crédito devem estar dispostos a aceitar o peso da responsabilidade" (p. 93, tradução do autor).

Um aspecto pouco explorado e discutido em nossa literatura sobre ética diz respeito à confidencialidade das informações que revisores e editores de periódicos científicos têm em função do seu trabalho. Nesse caso específico, a APA (2010a), indica que 
manuscritos sob revisão são confidenciais e devem ser tratados como um documento privilegiado. Assim, editores e revisores não podem citar o texto sem autorização expressa do autor, bem como revisores não podem discutir aspectos do artigo, mesmo que a título de aconselhamento com outros colegas, sem a autorização e o conhecimento do editor do periódico (APA, 2010a).

Como podemos perceber, a maioria das possíveis violações éticas acima apresentadas não são passíveis de serem identificadas pela ação de comitês de revisão. Elas dependem, fundamentalmente, da ação dos pesquisadores individuais. Entretanto, todas elas oferecem graves riscos à integridade da pesquisa, ao valor social da atividade científica e ao bem-estar da sociedade. Não queremos, com isso, sugerir que os CEPs são inúteis ou irrelevantes. Não é disso que aqui se trata. Na medida em que os comitês são compostos por pares que conhecem e dominam o campo de investigação, ele pode contribuir para elucidar/problematizar aspectos relevantes que muitas vezes passam despercebidos pelo pesquisador. Eles são igualmente relevantes naquelas situações onde o grau de risco ao participante é elevado, sendo, nesses casos, necessária uma análise independente que avalie se os benefícios são justificados frente ao risco e se mecanismos compensatórios são suficientes para compensar os eventuais danos causados. Essas argumentações visam mostrar que é um equívoco estruturar um sistema de regulação para a ética em pesquisa apenas em torno de instâncias burocráticas. $O$ foco do agir ético deve ser o pesquisador.

Este texto não teve como intenção esgotar todas as possibilidades e domínios de reflexão sobre ética em pesquisa. O ponto central de nossa argumentação girou em torno da ideia de que cabe ao pesquisador da área de POT, e não a um órgão burocrático externo, o papel principal no controle e na regulação da ética em pesquisa, reforçando elementos e caracterísitcas centrais explicitadas na resolução 510/2016 do CNS, ao propor um sistema misto de regulação baseado na noção de risco. Ao longo deste ensaio, buscamos explicitar o que isso significa, onde esta posição se localiza na literatura e quais os princípios gerais que a guiam. Buscou-se, ainda, mostrar que uma série de problemas éticos não são passíveis de serem identificados pelos CEPs, o que reforça ainda mais a centralidade do pesquisador. Na última seção, buscou-se discutir e operacionalizar alguns dos princípios anteriormente apresentados, sempre ressaltando a centralidade da ação do pesquisador nesse domínio.

Diante da importância dos aspectos éticos para a pesquisa, resta-nos apontar um conjunto de sugestões a serem adotadas pelos pesquisadores, de forma a auxiliar na sua reflexão e prática. Nesse sentido, adaptamos as diretrizes propostas pela União Europeia (EU, 2014), conforme indicado:

- A melhor forma de garantir um procedimento ético na pesquisa é torná-lo um elemento orgânico do seu projeto através de um diálogo contínuo com os demais elementos teóricos e metodológicos que o compõem. Ainda que no Brasil parte significativa da regulamentação ética em pesquisa na Psicologia seja aquela disponível nas resoluções do CNS, não significa que essa é a única fonte legítima de orientação.

- $\quad$ Recomenda-se que o pesquisador lance mão de outros códigos de ética, mesmo que escritos com o foco em outras áreas do conhecimento ou ainda outros países, como forma de auxílio nessa reflexão. Deve-se ter em mente que os princípios gerais que guima muitos destes códigos são aplicáveis em nossa cultura e refletem princípios e aspirações universais consagradas nas diversas cartas e tratados de direitos humanos.
- Lembre-se que a atividade científica é uma prática social baseada na confiança e na colaboração entre pesquisadores. Caso tenha algum tipo de dúvida sobre uma ação, método ou procedimento, não hesite em consultar e discutir a questão com um colega pesquisador. Não existem respostas certas e definitivas sobre como proceder eticamente.

E, por fim, mas não em último lugar, considerando que uma das atividades mais comuns do pesquisador consiste no treinamento de outros jovens pesquisadores, não podemos nos esquecer que o ensino sobre ética deve ser parte integral dessa formação.

\section{Referências}

Aguinis, H., \& Henle, C. (2004). Ethics in research. In S. Rogelberg (Ed.), Handbook of research methods in industrial and organizational psychology (pp. 34-56). Oxford: Blackwell Publishing.

Alliance for Organizational Psychology. (2016). Memorandum of understanding on fostering ethical, relevant and rigorous research. Recuperado de http://www. allianceorgpsych.org/Portals/6/Docs/AOP\%202016\%20MoUResearchfinal. pdf

American Psychological Association. (2010a). Ethical principles for psychologists and code of conduct. Washington: APA.

American Psychological Association. (2010b). Publication manual. Washington: APA.

Ardagh, D. (2007). The ethical basis for HRM professionalism and codes of conduct. In A. Pinnington, R. Macklin \& T. Campbell (Orgs.), Human resource management: Ethics and employment (pp. 152-170). Oxford: Oxford University Press.

Associação Brasileira de Psicologia Organizacional e do Trabalho. (2008). Psicologia como área de saúde: O risco de uma definição exclusiva. Recuperado de http://www.sbpot.org.br/institucional/relatorio-de-gestao/

Bastos, A. V. B., Yamamoto, O., \& Rodrigues, A. C. A. (2013). Compromisso social e ético: Desafios para a atuação em psicologia organização e do trabalho. In L. O. Borges \& L. Mourão (Orgs.), O trabalho e as organizações: Atuações a partir da psicologia (pp. 25-52). Porto Alegre: Artmed.

Barret, M. (2010). Questões práticas e éticas do projeto de pesquisa. In G. M. Breakwell, S. Hammond, C. Fife-Schaw \& J. A. Smith (Orgs.), Métodos de pesquisa em psicologia (pp. 42-63). Porto Alegre: Artmed.

Borges, L. O., Barros, S. C., \& Leite, C. P. R. L. A. (2013). Ética na pesquisa em psicologia: Princípios, aplicações e contradições normativas. Psicologia: Ciência e Profissão, 33(1), 146-161. doi: http://dx.doi.org/10.1590/ S1414-98932013000100012

British Psychological Society. (2014). Code of human research ethics. Leicester: British Psychological Society.

Bryman, A. (2005). Social research methods. Oxford: Oxford University Press.

Bucher-Maluschke, J. S. N. F. (2006). Ética e responsabilidade na pesquisa em psicologia: Considerações preliminares. Revista Humanidades, 21(1), 7-10.

Conselho Federal de Psicologia. (2013). Contribuições do Conselho Federal de Psicologia à formação da(o) psicóloga(o). Brasília: CFP.

Conselho Federal de Psicologia. (2014). Código de ética profissional do psicólogo. Brasília: CFP.

Durkheim, E. (1957). Professional ethics and civic morals. Londres: Routledge. Durkheim, E. (1999). Da divisão do trabalho social. São Paulo: Martins Fontes.

European Union. (2010). European textbook on ethics in research. Luxemburgo: Publications Office of the European Union.

European Union. (2013). Ethics for researchers. Luxemburgo: Publications Office of the European Union

Fontanella, B. J., Luchesi, B., Saidel, M. G., Ricas, J., Turato, E. R., \& Melo, D. G. (2011). Amostragem em pesquisas qualitativas: Proposta de procedimentos para constatar saturação teórica. Caderno de Saúde Pública, 27(2), 389-394. doi: http://dx.doi.org/10.1590/S0102-311X2011000200020

Gonzalez, A. M. (2000). Ética y moral: Origen de una diferencia conceptual y su transcendencia en el debate ètico contemporaneo. Anuario Filosófico, 33, 797-832.

Guerriero, I. Z. C., \& Dallari, S. G. (2008). The need for adequate ethical guidelines for qualitative health research. Ciência \& Saúde Coletiva, 13(2), 303-311. doi: http://dx.doi.org/10.1590/S1413-81232008000200002

Hoeyer, K., Dahlager, L., \& Lynöe, N. (2005). Conflicting notions of research ethics: The mutually challenging traditions of social scientists. Social Science \& Medicine, 61(8), 1741-1749.

Leitão, S., Falcão, J. T. R., \& Maluf, R. (2015). Ethical standards of scientific research involving human subjects in Brazil: Perspectives concerning 
psychology. Psicologia Reflexão e Crítica, 28(1), 40-48. doi: http://dx.doi. org/10.1590/1678-7153.2015284007

Organização das Nações Unidas para a Educação, a Ciência e a Cultura. (2006). Declaração universal sobre bioética e direitos humanos. Paris: UNESCO.

Passos, E. (2007). Ética e psicologia. São Paulo: Editora Vetor.

Research Councils UK. (2013). RCUK policy and guidelines on governance of good research conduct. Recuperado de http://www.rcuk.ac.uk/documents/ reviews/grc/rcukpolicyandguidelinesongovernanceofgoodresearchpracticefebruary2013-pdf/

Resnik, D. B. (2005). The ethics of science. Londres: Routledge.

Resnik, D. B. (2015). What is ethics in research \& why is it important? Recuperado de http://www.niehs.nih.gov/research/resources/bioethics/whatis/

Resolução $n^{\circ}$ 510, de 07 de abril de 2016 (2016, 07 de abril). Dispõe sobre as normas aplicáveis a pesquisas em Ciências Humanas e Sociais. Recuperado de http://conselho.saude.gov.br/resolucoes/2016/Reso510.pdf
Shuster, E. (1997). Fifity years later: The significance of the nuremberg code. The New England Journal of Medicine, 13, 1436-1440. doi: 10.1056/ NEJM199711133372006

Tri Council Policy Statement. (2014). Ethical conduct for research involving humans. Ottawa: Secretariat on Responsible Conduct of Research. Recuperado de http://www.pre.ethics.gc.ca/pdf/eng/tcps2-2014/TCPS_2_FINAL_Web. pdf

UK Integrity Research Office. (2009). Codes of practice for research. Londres: UK Research Integrity Office, Universities.

Victora, C. (2014). Ética e pesquisa: Dilemas e desafios para a antropologia. In T. C. Silva (Org.), Ciclo de estudos e debates: Procedimentos éticos e a pesquisa em antropologia (pp. 22-26). Goiânia: FUNAPE/UFG, ABA.

Whitbeck, C. (1995). Trust and trustworthiness in research. Science and Engeneering Ethics, 1, 403-416.

World Intellectual Property Organization. (s/d). What is intellectual property? Recuperado de http://www.wipo.int/edocs/pubdocs/en/intproperty/450/ wipo_pub_450.pdf 